\title{
Financial problems and psychological distress: Investigating reciprocal effects among business owners
}

\author{
Marjan J. Gorgievski'*, Arnold B. Bakker ${ }^{1,2}$, Wilmar B. Schaufeli², \\ Hennie B. van der Veen ${ }^{3}$ and Carin W. M. Giesen ${ }^{4}$ \\ 'Department of Industrial and Organisational Psychology, Erasmus University \\ Rotterdam, The Netherlands \\ ${ }^{2}$ Department of Social and Organizational Psychology, Utrecht University, \\ The Netherlands \\ ${ }^{3}$ Agricultural Economics Research Institute, The Hague, The Netherlands \\ ${ }^{4}$ Aiolos - Psychological Projects, Amsterdam, The Netherlands
}

\begin{abstract}
Building on conservation of resources theory and the dynamic equilibrium model, this three-wave longitudinal study among 260 Dutch agricultural business owners ( 1 -year time intervals) investigated reciprocal relationships between the financial situation of the business and psychological distress. Results of structural equation modelling analyses revealed a negative spiral of farm decline, in which psychological variables played a key role. Experiencing financial problems predicted psychological distress, and acted as a self-fulfilling prophecy by strengthening intentions to quit the business, which predicted a deterioration of the objective financial situation of the business I year later. Moreover, farmers experiencing more psychological distress were more likely to get caught in this negative spiral than business owners with better mental health, because they experienced more financial problems, irrespective of their objective financial situation. Long-term psychological distress rather than temporary fluctuations in distress levels accounted for this effect.
\end{abstract}

For most people, work has an obvious economic meaning, and lack of financial resources affects many central aspects of their lives (Brief \& George, 1991). Among business owners, the relationship between financial problems and well-being has received surprisingly limited attention considering the fact that they constantly need to deal with a range of financial issues, especially when compared to employees on payroll (e.g., Buttner, 1992; Lewin-Epstein \& Yuchtman-Yaar, 1991; McMullan, 1996). The central question in the present study is to what extent a poor objective financial

* Correspondence should be addressed to Dr Marjan J. Gorgievski, Department of Industrial and Organisational Psychology, Erasmus University Rotterdam, Rotterdam, The Netherlands (e-mail: Gorgievski@fsw.eur.nl). 
situation influences business owners' subjective experience of financial problems, intention to quit the business, and psychological distress. In addition, because wellbeing may affect performance, it will be investigated to what extent reversed effects occur. To our knowledge, only two earlier stress studies have incorporated both objective economic indicators (family income and the ratio of owned to borrowed capital) and subjectively experienced economic pressure into one study (Armstrong \& Schulman, 1990; Lorenz, Conger, Montague, \& Wickrama, 1993). These studies showed that a poor objective financial situation predicted experienced hardship, which, in turn, predicted depressive symptoms. However, the design of these studies did not allow for testing possible reversed effects. In contrast, the present study applies a three-wave longitudinal design that allows for firmer conclusions concerning a possible bidirectional nature of relationships between business performance and well-being.

\section{Empirical background}

We conducted our research among Dutch farmers. During the past decades, political and societal developments, including the changing policies of the European Community and growing global competition, have made financial issues a major concern for them. Increased production costs and decreased returns on agricultural products negatively affected the profitability of the farm business. Ample empirical evidence has related subjectively experienced financial problems to impaired mental and physical well-being of farmers (Duncan, Volk, \& Lewis, 1988; Eberhardt \& Pooyan, 1990; Giesen, 1991; Gorgievski-Duijvesteijn, 1999; Schulman \& Armstrong, 1989). Simultaneously, the agricultural sector was caught in a technological treadmill, the consequence of which was that staying the course was equivalent to failure. Hence, farmers needed to increase their business size and technological complexity dramatically in order to remain competitive (Berkhout \& Van Bruchem, 2006; Vidal, 2000). Many farmers who failed have quit, often with severe consequences for personal well-being (e.g., Rosenblatt, 1990).

As indicators of a poor objective financial situation this study focuses on three economic variables based on the farm's balance sheet that are indicative of the inability to meet basic financial requirements in the short, middle, and long term: liquidity, modernity, and solvency (Barry, Baker, \& Ellinger, 2000; Mulder, 1994). Liquidity problems mean that the total sum of income derived from product sales, off-farm work and already available liquid means is insufficient to finance expected expenditures, and tax and interest payments. Liquidity problems thus are expected to directly hinder entrepreneurs in their daily activities. Because most farms in The Netherlands are family businesses, in which the work and private domain are closely intertwined, this not only relates to running the business (e.g., buying forage for the animals), but also to fulfilling family needs (e.g., buying new clothes or a refrigerator; Gasson \& Errington, 1993). Financial problems in the middle term are indicated by insufficient modernity of the durable assets (e.g., buildings, machinery). This means that a business owner has not been able to finance replacement investments that are necessary to remain competitive, such as renovating buildings or replacing machinery. Finally, in the long term, the financial situation needs to be sufficient to finance large reorganizations or a possible take-over. To this end, the business needs to have sufficient solvency, which is indicated by the ratio of owned capital to borrowed capital. 


\section{Financial problems predict distress}

The theoretical framework of our study is an integration of conservation of resources (COR) theory (e.g., Hobfoll, 1998, 2001) and the dynamic equilibrium model of wellbeing (Duncan-Jones, Fergusson, Ormel, \& Horwood, 1990). In a nutshell, COR theory depicts stress as a process centred on the loss of important resources. According to COR theory, increasing resources is a basic human drive. Real or anticipated resource loss is expected to lead to psychological distress. This is particularly true when it concerns primary resources that relate to survival and basic human needs. (Anticipated) Resource loss is expected to set into motion a negative spiral of further losses, because replenishing the original loss requires the investment of other resources people possess. Resource-rich people are expected to be better able to use effective strategies than people who possess less (adequate) resources, and hence the latter group is expected to be more vulnerable to get trapped into stressful loss spirals of significant resources.

Why is it so important to emphasize these loss spirals, or within-person-changes, in the stress process? Following the dynamic equilibrium model of well-being (DuncanJones et al., 1990), we assert that psychological distress levels have a large, for most people low, characteristic baseline referred to as a person's constitution (GorgievskiDuijvesteijn, Bakker, Schaufeli, \& Van der Heijden, 2005; Ormel \& Schaufeli, 1991). In other words, distress levels resist change. Disruptions caused by external influences, such as financial problems, are expected to be relatively short lived. Internal, biological, and cognitive processes cause distress levels to return to their original, characteristic baseline. So, an increase in psychological distress caused by external influences should be conceptualized as relatively temporary, short-term deviations from people's baseline distress levels (see Figure 1).

In line with other stress theories (cf. Cox \& Griffiths, 1995), the current study considers objective stressors as antecedents in the stress process. When the objective financial situation as indicated by the balance sheet is insufficient to fulfil basic financial requirements, business operators are expected to experience financial problems, such as being in the red on the current account, not being able to replace worn out machinery, or not being able to receive additional loans (Hypothesis 1).

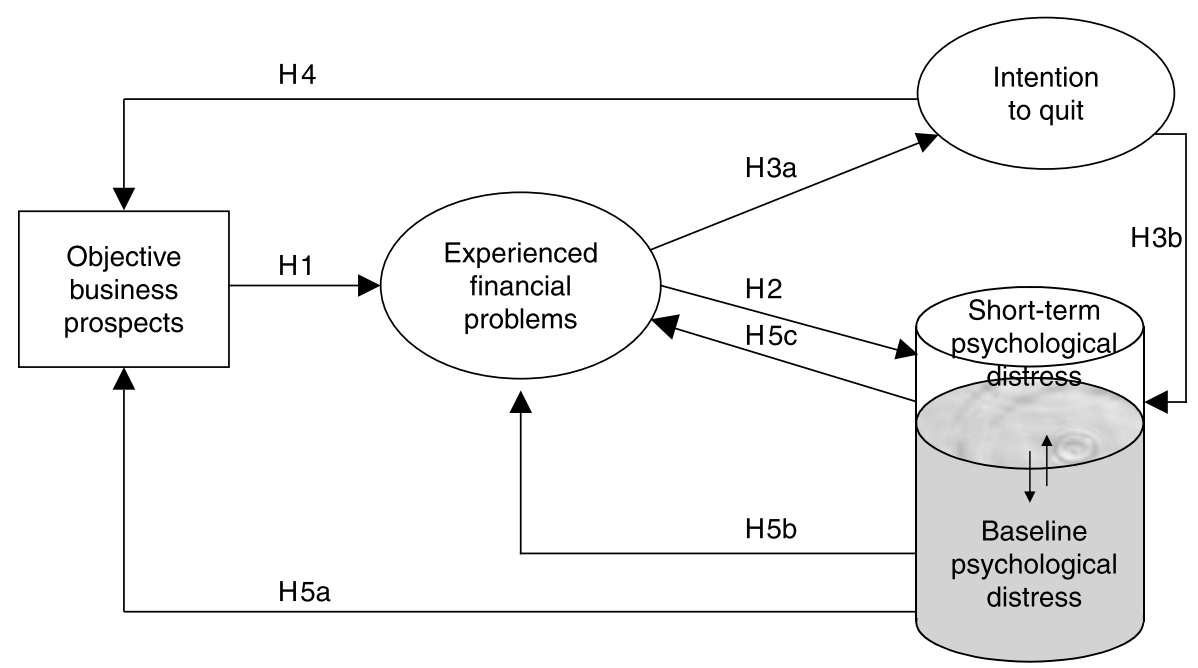

Figure I. Conceptual model. 
Subsequently, experienced lack of financial resources can be expected to set a loss spiral into motion. If financial problems persist, or worsen, over a longer period of time, business owners need to invest more and more important resources. Farmers with financial problems have been found to sell essential means of production, such as stocks and other assets, resulting in total depletion and technical bankruptcy (Mulder, 1994). Moreover, previous studies have shown that it is quite common for farmers to use their family's financial resources to solve financial problems at the farm, by cutting down family expenditures (e.g., Mulder, 1994; Rosenblatt, 1990), causing financial problems to cross over into the private domain (Gorgievski-Duijvesteijn, Giesen, \& Bakker, 2000). This stressful downward spiral of significant losses is expected to predict impaired wellbeing (cf. Hobfoll, 2001; Hypothesis 2).

Eventually, if business owners are unable to fulfil basic financial requirements, or need to sell essential means of production (e.g., land) in order to pay their bills, they may even feel that closing the business is inevitable. Therefore, we expect that the subjective experience of financial problems will foster farmers' intention to quit their business (Hypothesis 3a). Indeed, financial problems are often cited as the main cause of business closure (e.g., Amburgey \& Hayagreeva, 1996; Shepherd \& Douglas, 2000). Based on COR theory, we expect that the intention to quit the business also predicts increased psychological distress. Reason is the principle of primacy of loss over gain; according to which the stressful effect of resource loss is stronger than the positive effect of resource gain (Hobfoll, 1998, 2001). Dissolving the business may be a good strategy to minimize further financial losses, and therefore could be expected to relieve the distress related to working one's way through financial problems (cf. Lee \& Ashforth, 1993). However, this is not really a gain. In addition, quitting may open the way to exploring new opportunities, and to use remaining business resources in a more profitable way (cf. Meyer \& Zucker, 1989), but this would also require investments, and the returns would be quite uncertain.

Moreover, farmers can be characterized by human capital factors that have little value in other contexts, such as venture-specific knowledge and work-experience, which may reduce the number of attractive alternative options after quitting (e.g., Giesen, 1991; Rosenblatt, 1990). In addition, farmers are traditionally driven by deeper motives resulting from early socialization processes (e.g., Giesen, 1991; Rosenblatt, 1990). Farmers who face the question of whether or not to close the business may not only anticipate significant loss of prior investments, valued property and the most important source of income, but, more importantly, farming as a way of life. Not surprisingly, business closure has been shown to have a severe impact on the mental and physical health of those concerned (Rosenblatt, 1990). Therefore, we expect that the intention to quit will be a negative and stressful choice predicting psychological distress (Hypothesis 3b).

Our hypotheses will be tested in a three-wave longitudinal study with 1-year time intervals. Overall, the effects of financial problems are not expected to occur with a 1-year time lag. This relates to the expected effect of duration and the rate of change of financial problems (cf. George \& Jones, 2000). For example, it is more likely that farmers will intent to quit farming as a consequence of financial problems at the time these problems occur, than 1 or 2 years later once financial problems have been resolved. It may even be more likely that farmers intent to quit farming if they are experiencing financial problems in the second or third consecutive year. Likewise, based on the dynamic equilibrium model, increased psychological distress is conceptualized as a temporary deviation from a relatively stable, baseline distress level (see Figure 1). That 
means that we expect deviations in well-being to be restored over time, unless the situation deteriorates. In other words, we only expect financial problems occurring at one point in time to affect well-being 1 year later under the condition that they have aggravated, or somehow have led to other, secondary losses (cf. Hobfoll, Johnson, Ennis, \& Jackson, 2003). However, investigating the effect of patterns in financial developments over time on stress outcomes is beyond the scope of this article.

\section{Stress outcomes predict the objective and experienced financial situation}

The self-employed play a key role in their business. They provide most of the labour themselves and are primarily responsible for all management decisions (see Gasson \& Errington, 1993). Therefore, we argue business owners' behavioural responses to financial problems and psychological well-being will predict the financial situation of the business, and negative responses may accelerate loss spirals. Concerning the intention to quit, when business owners anticipate business closure, we expect them to start adjusting their business goals downward. Hence the intention to quit will deteriorate the objective financial situation of the business, and thus predict a poorer financial situation (Hypothesis 4). Because farmers anticipating business closure have recognized that their strategies are not viable, we expect their main focus will be to prevent further loss of business resources. In line with this expectation, empirical research has shown that up to 3 years before business closure, business owners stopped investing and started downsizing, leading to a decrease in financial performance (Almus, 2004; Van der Veen, Van Bommel, \& Venema, 2002).

In addition, we consider well-being as a personal resource that may influence both the objective financial situation as well as experienced financial problems. According to COR theory (e.g., Hobfoll, 1998, 2001), personal resources function as management resources, which help people to maintain a positive outlook and chose effective strategies in the face of adversities. Examples of strategies resulting in better individual performance that have been predicted by better psychological well-being, and which might ultimately affect business performance, relate to self-regulatory processes, such as goal setting and seeking feedback (e.g., Latham, Locke, \& Fassina, 2002; Trope \& Neter, 1994). In addition, anxiety and depressive symptoms have been found to impair information processing and decision making, leading individuals to rely on rigid, welllearned responses that may not be appropriate when facing major environmental changes (Ocasio, 1995; Staw and Barsade, 1993). Hence, poor well-being is expected to impair objective business performance. This expectation will be elaborated below.

We would anticipate reversed effects predicting the objective financial situation of the business to occur over a longer period of time of at least a few months. The objective financial situation is a rather indirect and stable conception of a performance outcome. Hence we expect it will take some time before decisions and actions flowing from intentions and impaired well-being take effect. Moreover, we expect the stable component of well-being - a person's constitution - rather than temporary distress levels to be the active ingredient (Hypothesis 5a). This was underscored by the results of a follow-up study of Dutch dairy farm couples (Gorgievski-Duijvesteijn et al., 2000), which showed that farmers' mental and physical health predicted financial problems the farm-couple experienced 10 years later. It seems unlikely that a temporary decrease in well-being could have such a long lasting effect.

Finally, business owners with poor mental well-being may experience a similar objective financial situation as less favourable than business owners with better mental 
well-being. We would expect colouring of subjective experience because of impaired psychological well-being to occur for the stable component of well-being (Hypothesis $5 \mathrm{~b}$ ), as well as for temporary fluctuations (Hypothesis 5c). One well-documented process is that psychological well-being relates to positive illusions about ones' own performance (e.g., Boyd-Wilson, Walkey, \& McClure, 2002; Taylor \& Brown, 1994). Vice versa, research has shown that people scoring high on negative affectivity, which closely relates to the stable component of psychological distress (Duncan-Jones et al., 1990; Ormel \& Schaufeli, 1991), may be more sensitive to negative information, and have more negative perceptions of the environment than people scoring low on this negative mood disposition (Burke, Brief, \& George, 1993; Spector, Zapf, Chen, \& Frese, 2000). This may be based on prior experience; similar objective situations may really be harder for more distressed people to cope with, for example, because they are less skilled and less able to generate social support.

\section{Method}

\section{Participants and procedure}

We asked 688 Dutch farmers and horticulturists, participating in the Farm Accountancy Data Network (Van Dijk, Groot, Lodder, \& Vrolijk, 1998) of the Dutch Agricultural Economics Research Institute (LEI-DLO), to fill out questionnaires during spring 1998, 1999, and 2000. Participants were 513 farmers (response rate $=75 \%$ ) in the first wave, 405 (59\%) in the second wave, and 363 (52\%) in the third wave; 302 farmers responded in every wave. The LEI-DLO calculated the farms' objective financial situation based on accountancy data (cf. Mulder, 1994). This data was collected 1 month (agriculture) to 4 months (horticulture) before the stress-survey. Calculations were possible for 287 of the 302 farms in 1998, 289 of the 302 farms in 1999, and 267 of the 302 farms in 2000. Records were complete for 260 businesses. Missing data were listwise deleted. ${ }^{1}$ Included were 251 men and 9 women between 24 and 63 years of age, with an average age of 44 years old at the start of the study $(S D=9.55)$. Mean farm-size was 118 European Size Units ${ }^{2}$ (ESU; $S D=80$ ).

Farmers who refused to participate in our study did not differ significantly from those who participated, with respect to business features (size, number of people working on the farm, and agricultural branch). Furthermore, farmers participating in all three data-waves did not differ significantly from those who dropped out concerning business-features (size, number of working hours, financial situation), family-features (family size, youngest child's age) and farmers' characteristics (age, psychological distress, and self-reported illness). Seven per cent of attrition $(N=36)$ was caused by respondents leaving the population.

\section{Measures}

The objective financial situation was calculated for each individual farm by means of a micro-simulation model (Mulder, 1994). This model took the current financial

\footnotetext{
'Analysing all 513 records using the full information maximum likelihood method for treating missing values (Arbucle, 2005) gave similar results as presented in this article.

${ }^{2}$ ESU are defined as units gross standard balance corrected for price developments in Europe (Berkhout \& Van Bruchem, 2006). Using ESU's allows a comparison of the size of businesses operating in different branches.
} 
characteristics of the farm business as a starting point (reflected in the flow of funds statement and the balance sheet). Then, based on a simulation of expected events in the following year concerning income (e.g., the price of agricultural products) and expenditures (e.g., tax payments, wages for workers, family income) ${ }^{3}$ the farm's liquidity, modernity, and solvency were calculated. In validation studies of the simulation model, the estimated financial developments on the individual farms closely matched the real annual developments (e.g., Baltussen \& Van der Veen, 1998; Landbouw Economisch Instituut, 1998; Mulder, 1994).

Liquidity, modernity, and solvency can be discriminated, but not separated. For example, if a farmer works with worn out machinery, he or she is expected to replace them in the near future. He or she can either choose to pay for this investment using liquid financial means (which would deteriorate the farm's liquidity), or by getting an additional loan (which might deteriorate solvency). Based on this notion, the outcome of the simulation program was a score for each farm between five and one, depending on whether they had sufficient liquidity, modernity, and solvency: (5) The farmer is expected to meet liquidity problems in the near future that he or she is not able to solve', (4) 'The farmer is expected to meet liquidity problems in the near future that he or she is able to solve by asking extra short-term loans, adjusting farm or family expenditures, or asking extension of payments', (3) 'The farmer is not expected to meet any liquidity problems. However, the farmer has not been able to do all replacement investments and is expected to have problems with doing them in the future. In addition, the farm's solvency is not so good', (2) 'The farmer is not expected to meet any liquidity problems. He or she has been able to do all replacement-investments and is not expected to have problems with doing them in the future. However, the farm's solvency is not so good', (1) 'The farmer is not expected to meet any liquidity problems. He or she has been able to do all replacement-investments and will also be able to do them in the future. Moreover, the farmer has good solvency'. Only if financial requirements in the short term were met (sufficient liquidity), the program calculated whether the farm had sufficient financial means in the middle term (sufficient modernity), and subsequently in the long term (sufficient solvency). If not, a score was assigned and the simulation terminated.

Experienced financial problems were measured with an eight-item scale, comprised of five items from Giesen (1991) and three items based on Mulder (1994). Examples are 'Lately, how often has it occurred that you did not have enough money to make ends meet?' and 'Lately, how often has it occurred that you had to work with worn out machinery because you lacked financial means to replace them?' Answers ranged from 1 'never or rarely' to 5 'very often'. Cronbach's alpha was .84 in 1998, .87 in 1999, and .85 in 2000.

Psychological distress was measured with a 12-item version of the General Health Questionnaire (GHQ; Goldberg, 1972). Example items are: 'Lately, have you felt unhappy and depressed?' 'Lately, have you felt capable of making decisions about things? (reversed coded)' and 'Lately, have you been thinking of yourself as a worthless person?' Respondents were asked to indicate the extent to which they had experienced any of these complaints during the preceding few weeks. Answer categories ranged from 1 'less than usual' to 4 'much more than usual'. Cronbach's alpha of the scale was

\footnotetext{
${ }^{3}$ A full description of the simulation model and simulated expected events can be found in Mulder (1994), or received from the first author on request.
} 
.86 for each of the 3 years. Methodologically we converted psychological distress measured at three time periods into a stable component over time (represented by a second order factor representing shared variance across the three time points) and unique factors (fluctuations) per measurement moment.

Intention to quit the business was measured by asking respondents to indicate the likelihood that the next 5 years they would: 'gradually cut down the business' or 'close the business, for instance by selling it'. Answers ranged from 1 'very unlikely' to 4 'very likely'. Internal reliability (Crohnbach's alpha) of the scale was .79 in 1998, .80 in 1999, and .78 in 2000. Logistic regression analyses showed that the intention to quit in 1998 and in 1999 both significantly predicted drop out caused by quitting the business $(N=17)$. For $1998, R=.38, B=1.31, S E=0.31, p<.001$ and for $1999, R=.28$, $B=0.99, S E=0.33, p<.005$.

\section{Strategy of analyses}

Hypotheses were tested using structural equation modelling (SEM) with the AMOS software package version 6.0 (Arbuckle, 2005). Prior to the SEM analyses, we ranked and normalized the left skewed raw scores of experienced financial problems and psychological distress, leading to skewness and kurtosis of less than 1.5. To examine how closely competing models fit to the data, we calculated (cf. Hu \& Bentler, 1999): (1) the chi-square likelihood ratio $\left(\chi^{2}\right),(2)$ Bonnet's non-normed fit index (NNFI), and (3) the root mean square error of approximation (RMSEA). The NNFI should be larger than .95 and the RMSEA should be below .05 .

\section{Results}

\section{The baseline model}

Prior to testing the hypothesized structural model, we constructed a baseline model in which psychological distress, intention to quit and experienced financial problems were modelled as latent variables. Because of the large number of items measuring psychological distress and experienced financial problems, we used a partial disaggregation model as recommended by Hall, Snell, and Faust (1999). This means that we created 'parcels' by taking the means of half of the items of a scale, and used two parcels per latent variable as observed indicators, rather than the single items of the scales. Significant covariances between error terms of identical measures over time were also modelled, as these are likely caused by systematic error not of theoretical interest, such as response bias (Fergusson \& Horwood, 1988). Loadings of the vectors connecting the indicators to the latent variables were all well above .70 . Covariations between latent factors are presented in Table 1.

All relationships between the variables in the baseline model were explained by covariances at the first wave of data collection and stability of the variables over time (see Figure 2). Stability of the objective financial situation, experienced financial problems, and intention to quit were represented by autoregressions, assuming that problems in 1 year predispose a person to experiencing further problems in the subsequent years. In line with the dynamic equilibrium model of well-being, stability in psychological distress was represented by a 'stability and change model' rather than autoregressions (cf. Duncan-Jones et al., 1990; Gorgievski-Duijvesteijn et al., 2005; Ormel \& Schaufeli, 1991). This model divides psychological distress into one higher 


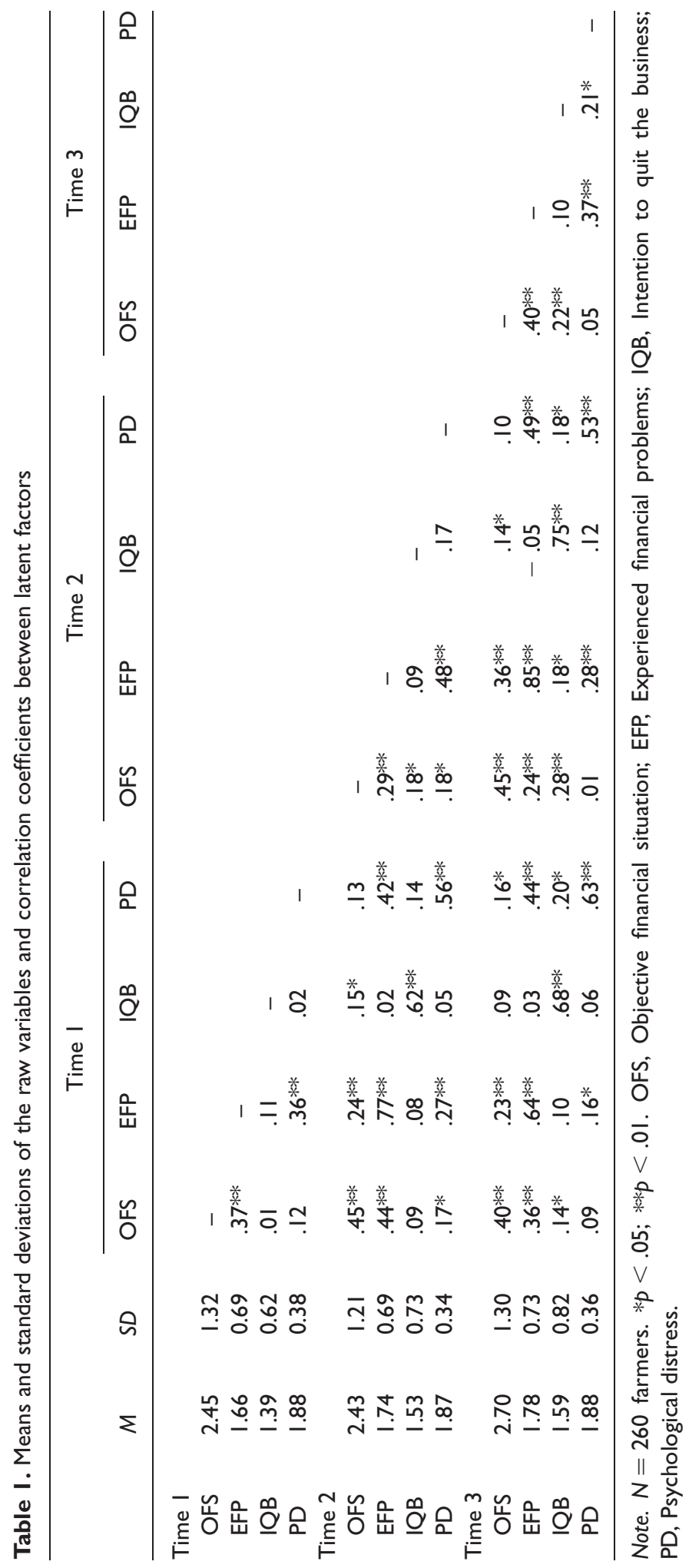




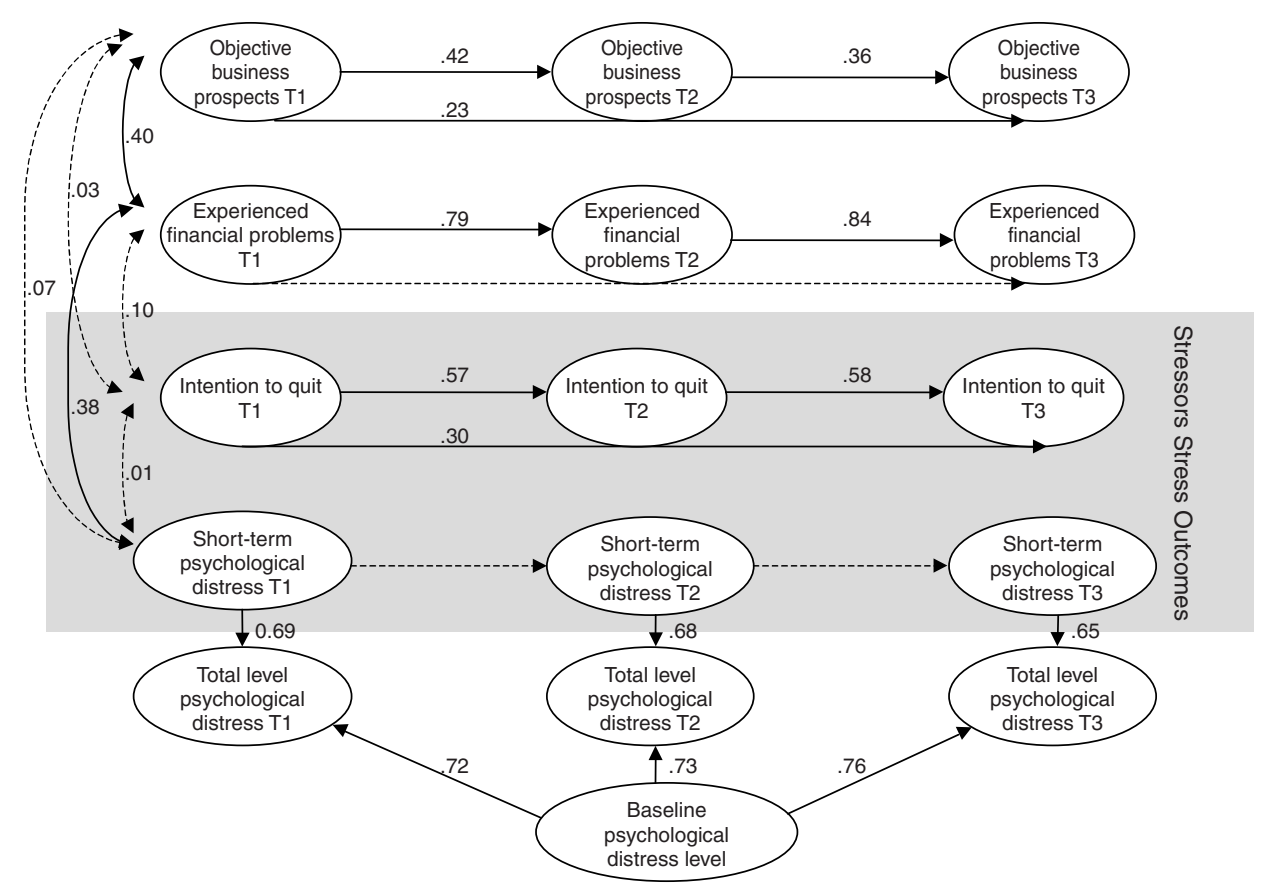

Figure 2. Baseline model. $\chi_{(174)}^{2}=317.39, p<.00 \mathrm{I}, \mathrm{CFI}=.95, \mathrm{NNFI}=.93, \mathrm{RMSEA}=.06, \mathrm{~N}=260$. Note. The baseline-model we tested also contained the observed indicators of the latent variables, error terms, and the vectors connecting the observed variables to the latent factors. These are not shown in the figure for reasons of clarity.

order factor of common variance across all three measurement moments, representing the stable baseline level. Additionally, three factors modelling the unique variance in psychological distress for each measurement moment represent temporary deviations in complaints at T1, T2, and T3. At T1, the baseline component explained $45 \%$ of variance in psychological distress, at T2 52\% and at T3 55\%. In line with previous studies (e.g., Duncan-Jones et al., 1990; Ormel \& Schaufeli, 1991), this indicates that only between 45 and $55 \%$ of the variance may be explained by external influences. For our data, the factors representing deviations in psychological distress were not significantly related over time. For reasons of parsimony, all identical relationships (in the non-standardized solution) were constrained to be equal across measurement moments, which did not significantly impair model fit. The fit of the baseline model to the data was good: $\chi^{2}(174)=314.73, p>.001, \mathrm{CFI}=.96, \mathrm{NNFI}=.94, \mathrm{RMSEA}=.05$.

\section{Testing the hypothesized structural relationships}

To test our hypotheses, we added the hypothesized structural relationships to the baseline model. Figure 3 shows the significant paths. Concerning the hypothesized concurrent stress effects of financial problems, full support was found. In line with Hypothesis 1, the objective financial situation predicted experienced financial problems. Note that the regression paths were modest $(\beta=0.12, p<.001)$, because most of the covariance was explained by the relationship at Time 1 , and stability of the variables over time. Correlations between the objective financial situation and 


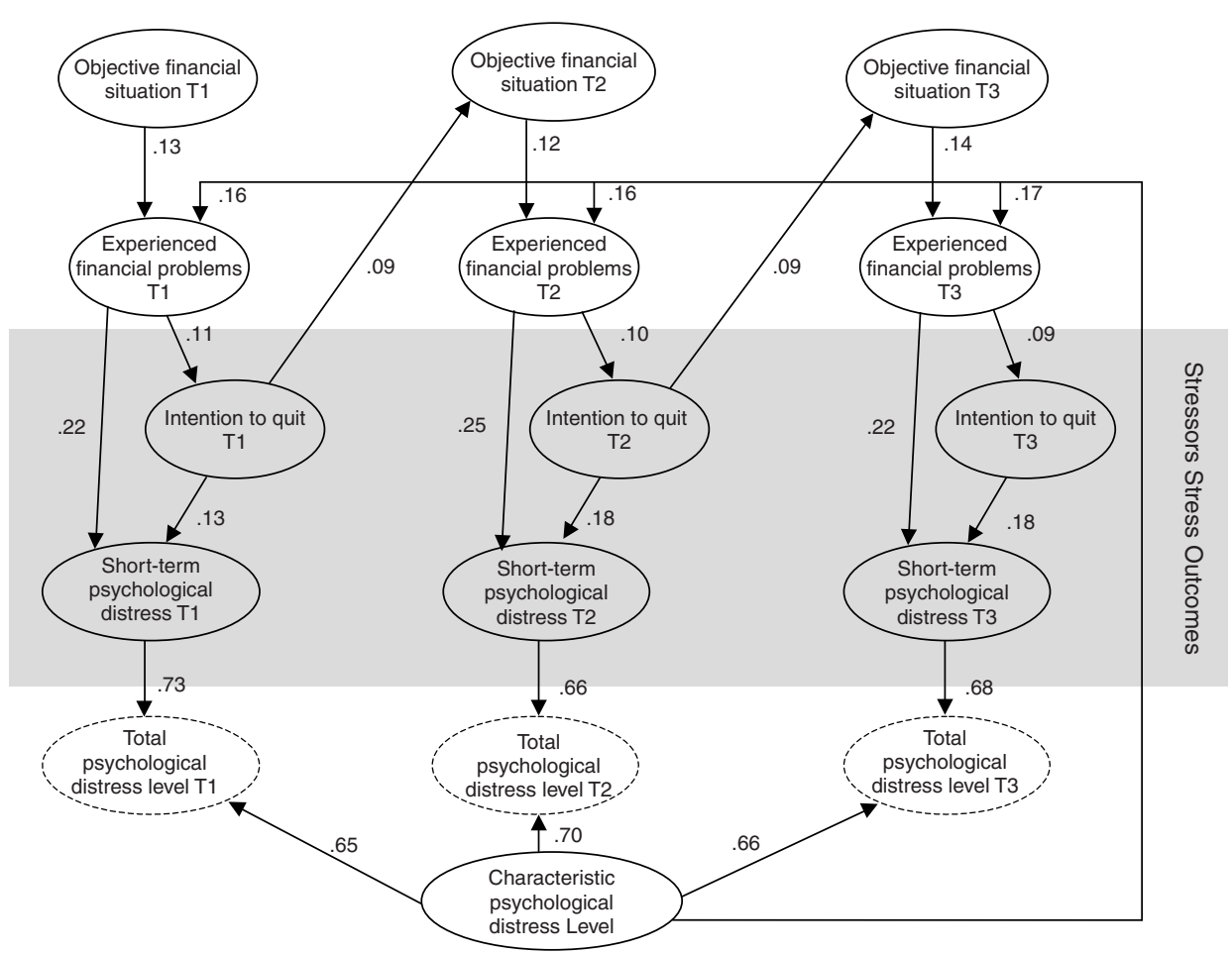

Figure 3. Final model. Relationships between a poor objective financial situation, experienced financial problems and stress outcomes. $\chi_{(168)}^{2}=230.60, p<.0 \mathrm{I}, \mathrm{CFI}=.98, \mathrm{NNFI}=.97, \mathrm{RMSEA}=.04$, $N=260$ farmers. Note. The figure only shows the significant hypothesized relationships between the latent variables. The tested SEM model also included all the relationships from the baseline model, which are not shown in Figure 3 for reasons of parsimony.

experienced financial problems ranged between $.28(p<.001)$ and $.37(p<.001 ;$ see Table 1).

Subsequently, supporting Hypothesis 2, experienced financial problems significantly predicted the temporary deviations in psychological distress. Note that paths leading from stressors to the stable component of psychological distress were not modelled, because it was theorized that this stable component is not influenced by temporary, external factors. Note that the standardized indirect effect of the objective financial situation on psychological distress was very small, .003 for each year. Results also supported Hypothesis $3 a$ and $3 b$, which predicted that experienced financial problems increase the intention to quit, which predicted additional psychological distress. The magnitude of this latter effect was small.

\section{Testing reversed effects}

Concerning possible lagged effects of stress outcomes on the objective financial situation, partial support was found as well. As predicted in Hypothesis 4, farmers' intention to quit their business at one point in time predicted a poorer objective financial situation 1 year later. This means that the intention to quit the business tended 
to consolidate over time, since a deteriorated objective financial situation, in turn, reinforced intentions to quit.

Concerning the effect of psychological distress on the financial performance of the business, only Hypothesis $5 b$ was supported. Farmers with high characteristic baseline levels of psychological distress experienced more financial problems than farmers with low baseline levels of distress on every measurement moment, irrespective of their objective financial situation. Hypotheses $5 a$, predicting that characteristic baseline levels of distress would predict a poorer objective financial situation and Hypothesis $5 c$, according to which short-term deviations in psychological distress levels would predict experienced financial problems, were rejected.

\section{Discussion and conclusions}

The current study tested bidirectional relationships between the objective financial situation of the business, business owners' perception of financial problems, and their stress responses. Because of the longitudinal design, and testing a unique structural equation model that separated baseline levels of distress from short-term deviations in distress levels within individuals, we gained two important new insights. First, this study showed that psychological variables were more important predictors of individual stress responses - short-term distress and behavioural intention to quit the business - than the objective financial situation was. Over time, individuals' behavioural stress response predicted a poorer objective financial situation. This indicates that perceptions of a poor financial situation may become a self-fulfilling prophecy. Second, this study showed that concerning a reversed causal relationship leading from psychological distress to finances, stable baseline levels of distress are the active ingredient rather than short-term distress. Baseline distress levels, and not short-term distress predicted perceived financial problems. We would not have been able to draw this conclusion using more traditional three-wave three-variable designs.

More specifically, we found that experienced financial problems were rooted in the objective financial situation of the business as calculated on the basis of an independent, objective data-source. This is in line with a previous farm-study showing that spouses agreed to a significant extent on the severity of experienced financial problems (Gorgievski-Duijvesteijn et al., 2000), which indicates that they do exist beyond farmers' individual experience. The strength of the relationships we found $(.29<r<.40)$ were similar to results obtained in earlier studies using farmers' selfreports of their debts to asset ratios (Armstrong \& Schulman, 1990; Lorenz et al., 1993). Even though it seems plausible that incumbents and experts do not base their judgments on the same information, the convergence in our study is stronger than has been found in job stress research among employees (see e.g., Spector \& Jex, 1991), which generally shows low convergence between incumbents' perceptions and expert ratings of job-characteristics $(r<.20)$.

Experienced financial problems concurrently predicted psychological distress and an increased intention to quit, which predicted additional psychological distress. Although most effects were small, they seem meaningful, since our tests were rather conservative. In line with our hypotheses we found that quitting the business may be a stressful process related to high (anticipated) losses. However, in the face of poor financial business prospects, business closure may be wise, because it allows for resources to be invested in other, more prosperous avenues. In such cases, people need 
support in order to stay focused on their resiliency rather than, for example, their sense of personal failure. In addition, possible gaps in their resource reservoirs needed for coping with the new situation need to be filled, in order to prevent the acceleration of loss cycles and loss of critical, primary resources, such as self-esteem, self-efficacy, and hope (Gorgievski \& Hobfoll, 2008; Hobfoll, 1998; 2001). Such a possible gap may relate to having only situation-specific human capital that has little value in other contexts. Situation-specific human capital has been found to block intentions to quit the business and to start another enterprise in spite of poor business performance (e.g., Gimeno, Folta, Cooper, \& Woo, 1997).

Concerning reversed causal effects, our results among the self-employed add to the growing body of knowledge for the key role of psychological well-being in the prediction of financial problems (Aldwin \& Revenson, 1986; Glickman, Tanaka, \& Chan, 1991; Gorgievski-Duijvesteijn et al., 2000), job-stressors (Frese \& Zapf, 1988; Spector \& Jex, 1991; Zapf, Dormann, \& Frese, 1996), and individual performance (e.g., Wright \& Bonett, 1997; Wright, Bonett, \& Sweeney, 1993). Moreover, our findings support a static as well as a dynamic vulnerability explanation. Farmers' diminished motivation to continue had a negative impact on the objective financial situation of the business over time (dynamic). These results are consistent with findings of stress studies among other occupations, for instance general practitioners, showing that withdrawal in the longterm leads to a further deterioration of the stressful situation (e.g., Bakker, Schaufeli, Sixma, Bosveld, \& Van Dierendonck, 2000).

In addition, people's characteristic psychological distress levels (their constitution), but not short-term fluctuations in distress levels, predicted whether farmers experienced financial problems. Farmers with low characteristic levels of well-being were more negative about their financial situation at each measurement moment, irrespective of their actual, objective financial situation (static). This, in turn, diminished their motivation to continue their business and increased short-term psychological distress. These results are in line with the current view that any relationship between stable personal attributes of the business owner and business performance would be mediated by situation-specific motivation, goals, and strategies of the business owner (Baum \& Locke, 2004; Rauch \& Frese, 2000).

Short-term psychological distress as a result of financial problems did not impair the financial situation over time. This contradicts with other studies that did not take the stable baseline of distress and well-being into account (e.g., Aldwin \& Revenson, 1986; Taris, Bok, \& Caljé, 1998), based on which researchers concluded that psychological distress resulting from experiencing stress would render a person even more vulnerable for further exposure to stressors. Based on our results, we can conclude that a stable level of psychological distress over time may be the active ingredient rather than such short-term distress.

\section{Study limitations and suggestions for further research}

One limitation of our study is that we addressed a specific sample, namely agricultural business owners, and hence the question remains as to what extent our results would generalize to other, perhaps more entrepreneurial business owners. In entrepreneurship and business research, very few studies have investigated the issue of business performance at the micro-level, including business owners' subjective experiences. Our results argue in favour of investigating separate contributions of both objective finances and subjective experiences. In line with current stress theories, our study shows that 
psychological variables are more important than the objective situation in explaining business owners' intentions to quit. This finding warrants the use of psychological concepts, such as appraisal, in business research seeking to find answers to questions such as why businesses grow, downsize, innovate, or go abroad (cf. Cooper \& Artz, 1995), which to date is not common practice.

Second, a longitudinal design and sophisticated analyses do not rule out alternative explanations. Most importantly, we cannot completely rule out third variable explanations, or the possibility that psychological distress predicted the intention to quit. Additionally, the baseline psychological distress level is not only influenced by forces internal to the individual, such as biological and cognitive processes. To some extent it also reflects environmental stability. Because baseline psychological distress is based on information collected at the same time other variables were measured, it might to some extent relate to stability in the financial situation, which is the predictor variable in the study. A next study might benefit from additionally measuring baseline psychological distress at another point in time.

Additionally, future research may address the question of 'what business owners with better mental health do differently?' Mechanisms that could be included to investigate in more detail how well-being affects business performance are goal setting, decision-making strategies, and business strategies (cf. Rauch \& Frese, 2000). Future research may also focus on mediating variables explaining how financial problems lead to psychological distress. From a conservation of resources perspective, one would obviously focus on whether experiencing financial problems leads to net loss of other resources, in particular personal resources, such as self-referent beliefs (cf. Armstrong \& Schulman, 1990; Lorenz et al., 1993; Pearlin, Lieberman, Menaghan, \& Mullan, 1981), social resources (cf. Lorenz et al., 1993; Vinokur, Price, \& Caplan, 1996), or material resources (cf. Hobfoll et al., 2003). Adding a focus on resource changes would mean testing even more sophisticated statistical models including within-person changes in stressors over time (cf. Chan, 2003).

\section{Practical and theoretical implications}

Concerning practical implications for counselling and entrepreneurship education, this study adds to our understanding of the role of distress in the process of financial business decline. As this study shows, business owners base the decision to quit their business on subjective experiences, which are coloured by the way they feel. Being unduly pessimistic about one's financial situation may become a self-fulfilling prophecy through diminished motivation to continue. It would help current and future business owners to understand the role of well-being in decision-making and motivation, and their link to business performance, in addition to self-knowledge concerning their own disposition. In addition, business owners may need to be trained to be more entrepreneurial in looking at the positive side of business exit as an opportunity and a possibility to free resources to start something new.

\section{Final conclusion}

Results of this study show that it is possible to gain more detailed insights into bidirectional relationships between stressors and well-being than we have to date, by defining more sophisticated research models. Specifically, research should take more steps towards combining within-person stability and change elements with more 
traditional between-person relationships. We hope that this paper will stimulate more researchers to explicitly take into account expected developments of well-being constructs over time, and address theoretical questions relating to the nature of wellbeing and resilience of individuals, and its consequences for stressor-strain relationships.

\section{References}

Aldwin, C. M., \& Revenson, T. A. (1986). Vulnerability to economic stress. American Journal of Community Psychology, 14, 161-175.

Almus, M. (2004). The shadow of death: An empirical analysis of the pre-exit performance of new German firms. Small Business Economics, 23, 189-201.

Amburgey, T. L., \& Hayagreeva, R. (1996). Organizational ecology: Past present and future directions. Academy of Management Journal, 39, 1265-1286.

Arbuckle, J. L. (2005). Amos 6.0 user's guide. Chicago, IL: SPSS Inc.

Armstrong, P. S., \& Schulman, M. D. (1990). Financial strain and depression among farm operators: The role of perceived economic hardship and personal control. Rural Sociology, 55, 475-493.

Bakker, A. B., Schaufeli, W. B., Sixma, H. J., Bosveld, W., \& Van Dierendonck, D. (2000). Patient demands, lack of reciprocity, and burnout: A five-year longitudinal study among general practitioners. Journal of Organizational Behavior, 21, 425-441.

Baltussen, W. H. M., \& Van der Veen, H. B. (1998). Bedrifseconomische effecten van dalende opbrengsten in de fruitteelt [Business economic effects of declining results in fruit growing]. The Hague: Agricultural Economics Research Institute.

Barry, P. J., Baker, C. B., \& Ellinger, P. N. (2000). Financial management in agriculture. Danville, IL: Interstate Publishers.

Baum, J. R., \& Locke, E. A. (2004). The relationship of entrepreneurial traits, skill, and motivation to subsequent venture growth. Journal of Applied Psychology, 89, 587-598.

Berkhout, P., \& Van Bruchem, C. (Eds.), (2006). Landbouw economisch bericht [Agricultural economic report]. The Hague: Agricultural Economics Research Institute.

Boyd-Wilson, B. M., Walkey, F. H., \& McClure, J. (2002). Present and correct: We kid ourselves less when we live in the moment. Personality and Individual Differences, 33, 691-702.

Brief, A. P., \& George, J. M. (1991). Psychological stress and the workplace: A brief command on Lazarus' outlook. Journal of Social Behavior and Personality, 6, 15-20.

Burke, M. J., Brief, A. P., \& George, J. M. (1993). The role of negative affectivity in understanding relations between self-reports of stressors and strains: A comment on the applied psychology literature. Journal of Applied Psychology, 78, 402-412.

Buttner, E. H. (1992). Entrepreneurial stress: Is it hazardous to your health? Journal of Managerial Issues, 4, 223-240.

Chan, D. (2003). Data analysis and modelling longitudinal processes. Group and Organization Management, 18, 341-365.

Cooper, A. C., \& Artz, K. W. (1995). Determinants of satisfaction for entrepreneurs. Journal of Business Venturing, 10, 439-457.

Cox, T., \& Griffiths, A. (1995). The nature and measurement of work stress: Theory and practice. In J. R. Wilson \& E. N. Corlett (Eds.), Evaluation of human work: A practical ergonomics methodology (2nd ed., pp. 783-803). Philadelphia, PA: Taylor and Francis.

Duncan, S. F., Volk, R. J., \& Lewis, R. A. (1988). The influence of financial stressors upon farm husbands and wives' well-being and family life satisfaction. In R. Marotz-Baden, C. B. Hennon, \& T. H. Brubaker (Eds.), Families in rural America: Stress, adaptation and revitalization (pp. 32-39). St Paul, MN: National Council on Family Relations.

Duncan-Jones, P., Fergusson, D. M., Ormel, J. O., \& Horwood, L. J. (1990). A model of stability and change in minor psychiatric symptoms: Results from three longitudinal studies. Psychological Medicine, Monograph supplement, 18, 1-28. 
Eberhardt, B. J., \& Pooyan, A. (1990). Development of the farm stress survey: Factorial structure, reliability and validity. Educational and Psychological Measurement, 50, 393-402.

Fergusson, D. M., \& Horwood, L. J. (1988). Structural equation modelling of measurement processes in longitudinal data. In M. Rutter (Ed.), Studies of psychological risk: The power of longitudinal data (pp.325-353). Cambridge: Cambridge University Press.

Frese, M., \& Zapf, D. (1988). Methodological issues in the study of work stress: Objective versus subjective measurement of work stress and the question of longitudinal studies. In C. L. Cooper \& R. Payne (Eds.), Causes, coping and consequences of stress at work (pp. 375-411). New York: Wiley.

Gasson, R., \& Errington, A. (1993). The farm family business. Wallingford, VT: CAB International.

George, J. M., \& Jones, G. R. (2000). The role of time in theory and theory building. Journal of Management, 26, 657-684.

Giesen, C. W. M. (1991). Werkverhoudingen en stress op bet boerenbedrijf [Stress and work issues among farm couples]. Amsterdam: Thesis Publishers.

Gimeno, J., Folta, T. B., Cooper, A. C., \& Woo, C. Y. (1997). Survival of the fittest? Entrepreneurial human capital and the persistence of underperforming firms. Administrative Science Quarterly, 42, 750-783.

Glickman, L., Tanaka, J. S., \& Chan, E. (1991). Life events, chronic strain, and psychological distress: Longitudinal causal models. Journal of Community Psychology, 19, 283-305.

Goldberg, D. P. (1972). The detection of psychiatric illness by questionnaire. London: Oxford University Press.

Gorgievski-Duijvesteijn, M. J. (1999). Job-involvement and stress in farm-couples. Gedrag en Gezondheid, 27, 109-117.

Gorgievski-Duijvesteijn, M. J., Bakker, A. B., Schaufeli, W. B., \& Van der Heijden, P. G. M. (2005). Finances and well-being: A dynamic equilibrium model of resources. Journal of Occupational Health Psychology, 10, 210-224.

Gorgievski-Duijvesteijn, M. J., Giesen, C. W. M., \& Bakker, A. B. (2000). Financial problems and health complaints among farm couples: Results of a 10-year follow-up study. Journal of Occupational Health Psychology, 5, 359-373.

Gorgievski-Duijvesteijn, M. J., \& Hobfoll, S. E. (2008). Work can burn us out and fire us up, conservation of resources in burnout and engagement. In J. R. B. Halbesleben (Ed.), Handbook of stress and burnout in health care (pp. 7-22). Hauppage, NY: Nova Publishers.

Hall, R. J., Snell, A. F., \& Foust, M. S. (1999). Item parceling strategies in SEM: Investigating the subtle effects of unmodeled secondary constructs. Organizational Research Methods, 2, 233-256.

Hobfoll, S. E. (1998). Stress, culture and community. The psychology and philosophy of stress. New York: Plenum.

Hobfoll, S. E. (2001). The influence of culture, community and the nested-self in the stress process: Advancing conservation of resources theory. Journal of Applied Psychology, 50, 337-396.

Hobfoll, S. E., Johnson, R. J., Ennis, N., \& Jackson, A. P. (2003). Resource loss, resource gain, and emotional outcomes among inner city women. Journal of Personality and Social Psychology, $84,632-643$.

Hu, L., \& Bentler, P. M. (1999). Cut-off criteria for fit indices in covariance structure analysis: Conventional criteria versus new alternatives. Structural Equation Modeling, 6, 1-55.

Landbouw Economisch Instituut (1998). Energiebesparingen in de glastuinbouw door financiële prikkels [Energy saving in horticulture under glass through financial incentives]. The Hague: Agricultural Economics Research Institute.

Latham, G. P., Locke, E. A., \& Fassina, N. E. (2002). The high performance cycle: Standing the test of time. In S. Sonnentag (Ed.), Psychological management of individual performance (pp. 201-228). Chichester, NY: Wiley.

Lee, R. T., \& Ashforth, B. E. (1993). A further examination of managerial burnout: Toward and integrated model. Journal of Organizational Behavior, 14, 3-20. 
Lewin-Epstein, N., \& Yuchtman-Yaar, E. (1991). Health risks of self-employment. Work and Occupations, 18, 291-312.

Lorenz, F. O., Conger, R. D., Montague, R. B., \& Wickrama, K. A. S. (1993). Economic conditions, spouse support, and psychological distress of rural husbands and wives. Rural Sociology, 58, 247-268.

McMullan, W. E. (1996). An entrepreneurial tragi-comedy: Exploring the dark side of venturing. Technovation, 16, 515-517.

Meyer, M. W., \& Zucker, L. G. (1989). Permanently failing organizations. Newbury Park, CA: Sage.

Mulder, M. (1994). Bedrijfstakverkenning en financiële analyse: Een simulatiemodel voor de glastuinbouw [Sector exploration and financial analysis: A simulation model for borticulture under glass]. The Hague: Agricultural Economics Research Institute, Report no. 126.

Ocasio, W. (1995). The enactment of economic adversity: A reconciliation of theories of failureinduced change and threat-rigidity. Research in Organizational Behavior, 17, 287-331.

Ormel, J. O., \& Schaufeli, W. B. (1991). Stability and change in psychological distress and their relationship with self esteem and locus of control: A dynamic equilibrium model. Journal of Personality and Social Psychology, 60, 288-299.

Pearlin, L. I., Lieberman, M. A., Menaghan, E. G., \& Mullan, J. T. (1981). The stress process. Journal of Health and Social Behavior, 22, 337-356.

Rauch, A., \& Frese, M. (2000). Psychological approaches to entrepreneurial success: A general model and an overview of findings. In C. L. Cooper \& I. T. Robertson (Eds.), International review of industrial and organizational psychology (Vol. 15, pp. 101-141). New York: Wiley.

Rosenblatt, P. C. (1990). Farming is in our blood. Farm families in economic crisis. Ames, IA: Iowa State University Press.

Schulman, M. D., \& Armstrong, P. S. (1989). The farm crisis: An analysis of social psychological distress among North Carolina farm operators. American Journal of Community Psychology, $17,423-440$.

Shepherd, D. A., \& Douglas, E. J. (2000). New venture survival: Ignorance, external shocks, and risk reduction strategies. Journal of Business Venturing, 15, 394-411.

Spector, P., \& Jex, S. (1991). Relations of job characteristics from multiple data sources with employee affect, absence, turnover intentions and health. Journal of Applied Psychology, $76,46-53$.

Spector, P. E., Zapf, D., Chen, P. Y., \& Frese, M. (2000). Why negative affectivity should not be controlled in job stress research: Don't throw out the baby with the bath water. Journal of Organizational Behavior, 21, 79-95.

Staw, B. M., \& Barsade, S. G. (1993). Affect and managerial performance: A test of the sadder-butwiser vs. happier-and-smarter hypotheses. Administrative Science Quarterly, 38, 304-331.

Taris, T. W., Bok, I. A., \& Caljé, D. G. (1998). On the relation between job-characteristics and depression: A longitudinal study. International Journal of Stress Management, 5, 157-167.

Taylor, S. E., \& Brown, J. D. (1994). Positive illusions and well-being revisited: Separating fact from fiction. Psychological Bulletin, 116, 21-27.

Trope, Y., \& Neter, E. (1994). Reconciling competing motives in self-evaluation: The role of selfcontrol in feedback seeking. Journal of Personality and Social Psychology, 66, 646-657.

Van der Veen, H. B., Van Bommel, K. H. M., \& Venema, G. (2002). Vestigingssteun voor bedrijfsopvolgers in de land- en tuinbouw, een vergelijking van 3 mogelijke varianten [Financial support for succession in agriculture and borticulture, a comparison of three possibilities]. The Hague: Agricultural Economics Research Institute.

Van Dijk, J. P. M., Groot, J. J. P., Lodder, K., \& Vrolijk, H. C. J. (1998). De steekproef voor het bedrijven informatienet van bet LEI; Bedrijfskeuze 1999 en selectieplan 2000 [The sample for the farm accountancy data network; choice of businesses 1999 and plan of selection 2000]. The Hague: Agricultural Economics Research Institute. 
Vidal, C. (2000). Thirty years of agriculture in Europe: Farm numbers decline as farms grow in size. Statistics in Focus, 5, 1-7.

Vinokur, A. D., Price, R. H., \& Caplan, R. D. (1996). Hard times and hurtful partners: How financial strain affects depression and relationship satisfaction of unemployed persons and their spouses. Journal of Personality and Social Psychology, 71, 166-179.

Wright, T. A., \& Bonett, D. G. (1997). The role of pleasantness and activation-based well-being in performance prediction. Journal of Occupational Health Psychology, 2, 212-219.

Wright, T. A., Bonett, D. G., \& Sweeney, D. A. (1993). Mental health and work performance: Results of a longitudinal field study. Journal of Occupational and Organizational Psychology, 66, 277-284.

Zapf, D., Dormann, C., \& Frese, M. (1996). Longitudinal studies in organizational stress research: A review of the literature with reference to methodological issues. Journal of Occupational Health Psychology, 1, 145-169.

Received 9 March 2007; revised version received 2 February 2009 